\title{
North Carolina Books
}

\section{Compiled by Al Jones}

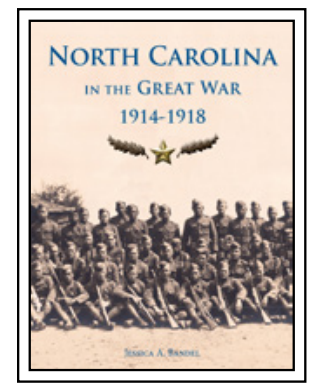

\section{North Carolina and the Great War, 1914-1918}

By Jessica A. Bandel. Raleigh: North Carolina Office of Archives and History, 2017. Viii, 152 pp. \$30.00. ISBN 978-0-86526-485-4.

$\mathrm{T}$ he broad features of the United States' entry into the First World War-the country's uneasy neutrality until 1917, the general uprush of patriotic fervor and enthusiastic support following the declaration of war, the sudden violent introduction to the horrors of 20th century warfare-are widely and even universally known and understood, especially in the midst of the commemoration of the 100th anniversary of the conflict. Less well known, or perhaps less generally acknowledged, are the thousands of quotidian details about the people who played some part in the war. The social and intellectual structures that were created and the material resources that were marshalled and deployed left thousands of memorials, both real and emotional, all of which tend to get lost as newer crises emerge and time scars over the old wounds or silences those who can still remember.

Books such as Jessica Bandel's North Carolina and the Great War, 1914-1918, go a long way towards redressing this imbalance. The author, a research historian at the North Carolina Office of Archives and History, has gathered together an impressive variety of military memorabilia, artifacts, photographs, and even ideas, and presents them as part of a coherent whole. Taking a cue from the format perfected by DK Publishing, Bandel essentially presents a museum exhibit in a book, providing a wide ranging and thorough examination of the role North Carolina played in the war. Each two-page spread combines lavish color illustrations with a short and well-researched essay about a specific topic, including expected subjects like weapons and equipment, life in the trenches, and well-known personalities such as Josephus Daniels and Walter Hines Page, as well as more unfamiliar subjects like the Hot Springs Internment Camp, the USS Cyclops, and the contributions of the Eastern Band of Cherokee to the war effort. Also included are six "Through the Lens" segments that consist of a single photograph with an appropriate contemporary quotation and short essay that highlights a particular aspect of the war, as well as 8 "exhibits," which gather together and caption similarly themed artifacts (many of them owned by North Carolina veterans or surviving relatives).

The book can be read in a traditional linear fashion, but the multifaceted, almost Pointillist arrangement of themes allows a multitude of entry points, so that the reader can delve into the conflict from a variety of angles without ever losing sight of the whole. A solid index and bibliography provide additional means of study and investigation. The book certainly doesn't treat any subject exhaustively, but, especially if read in conjunction with books such as Jackson Marshall's Memories of World War I: North Carolina Doughboys on the
Western Front and Sarah Lemmon and Nancy Midgette's North Carolina and the Two World Wars, the reader can build up a remarkably thorough picture of the war as it affected and was affected by the people of the state.

Recommended for all North Carolina libraries.

\section{Steven Case \\ State Library of North Carolina}

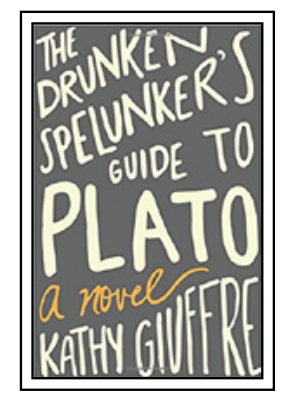

The Drunken Spelunker's

Guide to Plato

By Kathy Giuffre.

Winston-Salem, NC: John F. Blair, 2015, 223 pp. \$26.95. ISBN978-0-89587-651-5

Ciuffre employs an intriguing $\checkmark$ parallel in The Drunken Spelunker's Guide to Plato, using Plato's philosophical allegory of the Cave from The Republic. In using this parallel, Giuffre develops a rich, thought-provoking work, from an otherwise simple story of a southern girl's transition from adolescence to adulthood.

The tale is narrated by young Josie, a recent transplant from the Appalachian backwoods. Josie, arriving alone and uncertain in Waterville, finds her place in the cast of characters who frequent the Cavern Tavern, a local bar in the Waterville State College town. Josie tends bar, meets the "regulars" 
and becomes entrenched in the accepting community she finds there. This cast of characters is not that far removed in some aspects from those in Plato's joyless band of prisoners confined in the cave in his Republic. Some of the bars "regulars" seem never able to move beyond the confines of their own Cavern, the bar, much like Plato's humans who are forever chained in their cave. Readers will recognize that we all struggle on our way to the truth and the light, experiencing our own personal shackles, depths and heights. The subtle wit in Josie's narration brings humor, humanness, and light showing the mix of emotion, depth and caring in these customers so firmly tied to the Cavern. Growth comes to Josie too, through finding her place in this new community.

The parallel in The Drunken Spelunker's Guide to Plato with Plato's allegory illuminates the sameness of community across the spectrum of society. Giuffre highlights a subculture prevalent in current society, and links it to the timeless work of a great philosopher. Readers will find this work thought-provoking as the story unfolds. Frequent references to Edith Hamilton's Mythology in addition to Plato's allegory leave readers with a sense of having read something more than just a novel.

This book is recommended for those interested in community or sociology from the southern Appalachian region. Public and academic libraries that collect North Carolina or Appalachian fiction should definitely have The Drunken Spelunker's Guide to Plato in their collections. High school libraries may wish to acquire this book as well.

\section{Kaye Dotson}

East Carolina University

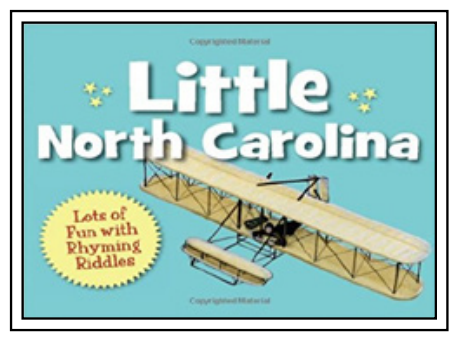

\section{Little North Carolina}

By Carol Crane.

Ann Arbor, MI: Sleeping Bear Press, 2011

20 pp. \$9.95 ISBN 9781585365456.

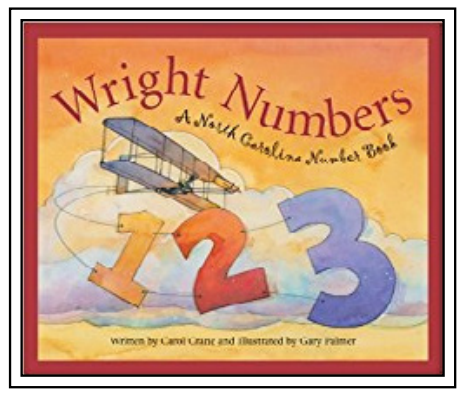

\section{Wright Number: A North Caro- lina Number Book}

By Carol Crane.

Ann Arbor, MI: Sleeping Bear Press, 2005

40 pp. 17.95 ISBN 9881585360826.

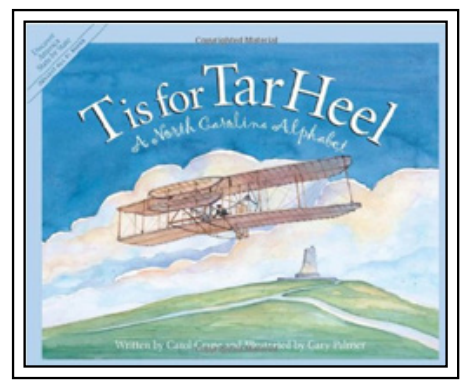

T is for Tar Heel: A North Carolina Alphabet

By Carol Crane. Ann Arbor, MI: Sleeping Bear Press, 2003 40 pp. 17.95 ISBN 9781585360826.

C hildren's author Carol Crane has written three books which children's librarians will want for their collections. All three contain information about the majestic mountains, the rolling foothills of heartland, and the beautiful beaches of glorious North Carolina!

Recently I had the pleasure of reading all three of these wonderful books about North Carolin published by Sleeping Bear Press with my grandchildren. All three books, each in a different format, introduce children to the splendor of North Carolina.

Little North Carolina, part of a series of board books about different states, uses rhyming riddles and a combination of clues and answers to introduce children to information about North Carolina in a fun and interactive activity. There is information about the state bird, flower, trees, animals and more. The rhyming format of the book, illustrations, and colorfulness made this book an easy-read to entertain my 2-year-old granddaughter. It is small enough for a toddler to hold and the pages are easy to turn.

Another fun way to introduce children to North Carolina is to let them count their way through the state or use the alphabet to introduce them to favorite and little-known places. Carol Crane's books, Wright Number: A North Carolina Number Book and $T$ is for Tarheel: A North Carolina Alphabet, both utilize rhymes for young readers to explore North Carolina from the coast to the mountains. From Pilot Mountain to Biltmore Mansion to Moravian cookies to the $\mathrm{Z}$ for zoom (the sound NASCAR racing cars make), children learn about their own hometown and other interesting facts about North Carolina. Each topic in both books is introduced with a poem and detailed information. At the end of $T$ is for Tarheel: A North Carolina Alphabet, questions are provided to test what was learned from the information that was read. What a great way for children to learn more about our State!

$T$ is for Tarheel: A North Carolina Alphabet and Wright Number: A North Carolina Number Book are recommended for ages 4 to 10; and Little North Carolina is recommended for infants to 3-year olds.

\section{Lou Sanders Sua \\ East Carolina University}




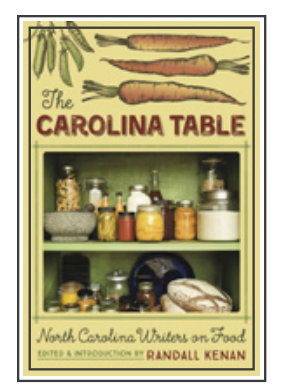

The Carolina Table:

North Carolina Writers on Food

Randall Kenan, ed.

Hillsborough, NC: Eno Publishers, 2016. 208 pp.

Soft cover, \$17.95 ISBN 978-0-9973144-0-3.

7 he Carolina Table is both a soulboard of thoughts on food in poetry and prose. Editor Randall Kenan, raised in Chinquapin, North Carolina, is an award-winning author who has set much of his work in the South and brought the ties between human relationships and food to the fore. He opens the collection with an essay that establishes the tone for a literary gustatory experience. Kenan asks, "Can there be a North Carolina without sweet potatoes, blueberries, or cucumbers?" (p. 6).

If you grew up in the Carolinas, or have lived here for a while, this collection will resonate strongly with you. The iconic foods, like grits and pimento cheese and home-grown tomatoes, and the cooking items, like Crisco shortening and Hellman's mayonnaise are present (I personally prefer Duke's, but Hellman's is a close second). The authors recall the family reunions, church functions, holiday meals, ladies' gatherings, and more, where food is a central player. Then there are the memories of a family member's cakes, pies, seafood. Food is inextricably entwined in our history and culture.

Jill McCorkle remembers her grandmother's pound cake, David H. Wallace rhapsodizes over the Lexington Bar-BQ-Center, Celia Rivenbark tells of a summer waitressing at Norris' Restaurant in the Duplin County town of
Wallace, and there is so much more. Each selection is a tiny jewel of southern foodways.

Recent trends are not excluded. Raleigh's Sophia Woo talks about her Pho Nomenal Dumpling food truck, where she serves Asian-inspired food with a Southern twist, and Paul Cuadros celebrates Alpaca's Peruvian Charcoal Chicken in Durham, which serves mouth-watering Peruvian dishes. There is a healthy belief that new culinary ideas don't threaten the traditional southern foodways, but expand and enhance them.

The contributors are fiction writers, poets, editors, food truck owners, chefs, cookbook authors, journalists, and foodways scholars. Most of the selections in the collection contain at least one recipe. I can tell you first hand that Fran McCullough got it right in her recipe for Better Butter Beans; it is just like my mama cooked them. In keeping with this fine example of unexpected gift giving, I would like to offer my mama's recipe for grated sweet potato pudding, which was a staple at family holiday dinners.

\section{Carolyn Wise's Grated Sweet Potato Pudding}

- 2 cups raw sweet potatoes, pared and grated

- $1 / 4$ cup melted butter

- 1 teaspoon lemon peel

- $1 / 4$ teaspoon ground ginger

- $1 / 4$ teaspoon ground cloves

- $1 / 2$ teaspoon ground cinnamon

- 1 cup brown sugar, firmly packed

- 2 eggs, well beaten

- $1 / 2$ cup milk

- $1 / 2$ cup chopped nuts

Grate potatoes. Combine next six ingredients with potatoes. Add milk to well-beaten eggs and blend with potatoes. Pour into greased 1-quart casserole. Top with nuts. Bake at 325 degrees for an hour. Serve warm.
The Carolina Table is an excellent companion to The Edible South: The Power of Food and the Making of an American Region by Marcie Cohen Ferris (UNC Press, 2014) and the Combread Nation: The Best of Southern Food Writing series, now in its seventh volume. The Carolina Table is recommended for all libraries with an interest in southern culture and foodways.

\section{Suzanne Wise \\ Appalachian State University}

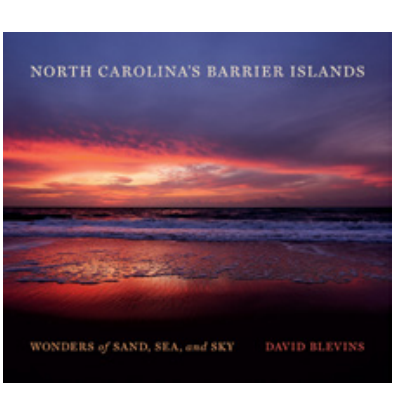

North Carolina's Barrier Islands: Wonders of Sand, Sea, and Sky

By David Blevins.

Chapel Hill: University of North Carolina Press,

2017. 188 pp. \$35.00. ISBN 978-1-4696324-9-0.

W $\begin{aligned} & \text { hat do rising seas, distinctive } \\ & \text { wildlife nesting areas, Cape }\end{aligned}$ Hatteras National Seashore, Cape Lookout National Seashore, sea oats, snow geese, loggerhead turtles, and Shackleford Banks stallions have in common? Visitors to North Carolina's barrier islands can locate all of these features on barrier islands at any given moment. North Carolina's Barrier Islands: Wonders of Sand, Sea, and Sky provides readers with a detailed description of each North Carolina barrier island and the wildlife or ecological features which are particular to the area. By definition, a "barrier island" is a geographic feature/island which acts as a buffer or "barrier" between the open ocean and sounds, marshes, or the mainland coastline communities. David Blevins explains to readers some of the conditions 
which form barrier islands, including rising seas, a movable continental shelf, available sand supply, and the presence of waves to move the sand. Throughout the pages of the book, the author details the specific wildlife found on each barrier island and concludes with the factors which make these islands distinctive and worthy of conservation.

Blevins divides his book into four sections: Currituck Banks, Cape Hatteras National Seashore, Cape Lookout National Seashore, and the Southern Islands. Each section contains a brief narrative followed by accompanying color photographs which illustrate the wildlife or ecological features of each island. Specifically, the color photographs include pictures of estuarine nature preserves, live oaks, sanderlings, royal terns, tundra swans, American beech trees, and hognose snakes. The author includes an index, a map which outlines the specific names of North Carolina barrier islands, and a multitude of color photographs. Each chapter title follows a specific detail of the map provided at the beginning of the book. Readers are taken on a journey from the North Carolina/ Virginia coast all the way southward to the North Carolina/South Carolina border.

David Blevins is a nature photographer and forest ecologist. The purpose of his books is to aid the reader in forming an appreciation of nature preservation or conservation of the barrier islands as natural wonders of the "Tar Heel State." Besides North Carolina's Barrier Islands, David Blevins has also written Wild North Carolina: Discovering the Wonders of Our State's Natural Communities (2011).

North Carolina's Barrier Islands offers readers a glimpse into the fragile ecosystem of the barrier islands off the North Carolina coast, and is a call to action for human beings to help protect and not overdevelop these islands. In the long run, human beings need to collaborate with the barrier islands so that these islands can be preserved for future generations to enjoy. Because of the book's specific scope and content, it would be appropriate for any public, special or academic library with a biology or ecology focus.

\section{David W. Young \\ University of North Carolina at Pembroke}

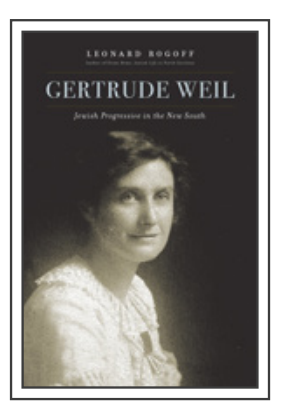

\section{Gertrude Weil: Jewish}

\section{Progressive in the New South}

By Leonard Rogoff.

Chapel Hill: University of North Carolina Press, 2017. 368 pp. ISBN 978-1-4696-3079-3. Cloth, \$35.00.

T eonard Rogoff, research historian Lfor the Jewish Heritage Foundation of North Carolina, is author of several books on Jewish life and culture, including Down Home: Jewish Life in North Carolina (UNC Press, 2010). He used here-to-fore untapped archival sources for this major biography of Gertrude Weil. His meticulously documented bibliographical notes lead readers to primary sources in the Weil Family Papers in the Southern Historical Collection, the University of North Carolina at Chapel Hill, the Gertrude Weil Papers at the State Archives of North Carolina in Raleigh, and the Rubenstein Rare Book and Manuscript Library at Duke University.

Gertrude Weil (1879-1971), was born, raised, and died in Goldsboro, Wayne County, North Carolina. Her parents, Henry and Mina Rosenthal
Weil, were part of a group of German Jews, who entered the United States through Baltimore and from there migrated to eastern North Carolina to begin new lives as department store proprietors, dry goods merchants, and haberdashers in small eastern North Carolina towns, including Goldsboro, where Henry was the proprietor of the Weil Department Store. Other German Jews established department stores, dry goods stores, and haberdasheries, including, but not limited to, Rosenblooms and Levys in Rocky Mount, Suskins in Washington, Adlers in Tarboro, Meyers in Enfield, Stadiems in Kinston, and Manns in Whiteville.

Gertrude and her family were Reform Jews who did not adhere to orthodoxy, including keeping kosher and observing travel restrictions on the Sabbath. Judaism's mission of "tikkun olam," that is, to "repair the world" by acting constructively for the benefit of all humankind, was the driving force of Gertrude's existence. She summed up her philosophy succinctly, "[i]t is so obvious that to treat people equally is the right thing to do."

An ardent suffragette, Gertrude founded North Carolina's League of Women Voters, and advocated for labor reform, including child labor, social welfare, and world peace. She was a lifetime member of the North Carolina Association of Jewish Women.

Just before World War I when Hitler seized power in Germany, Gertrude dedicated herself to saving her European family members from the Holocaust, including Rosenbaums, Oettingers, Fischers, Birnbaums, and Lederers. After World War II, Gertrude lent her enthusiastic support as a Zionist to the creation of the Jewish state of Israel in 1948.

As a Progressive reformer and committed idealist in what was dubbed the New South after Reconstruction, 
Gertrude lent her positive spirit and inspired others to activism locally, statewide, nationally, and internationally. She was in every way a citizen of the world. Not only in Goldsboro, but throughout the world, humanitarians will continue to look toward the commitment and determination of Gertrude Weil. Her life was an inspiration in the twentieth-first century fight for civil and human rights.

This biography should be in every academic and public library, particularly those with a North Carolina focus.

\section{Al Jones}

East Carolina University

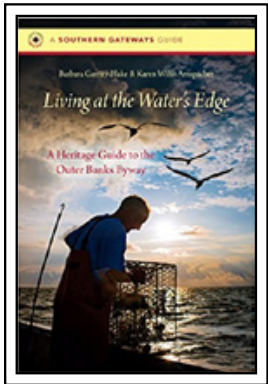

Living at the Water's Edge: A Heritage Guide to the Outer Banks Byway

By Barbara Garrity-Blake and Karen Willis Amspacher Chapel Hill: University of North Carolina Press, 2017. 320 pp. \$22.00. ISBN 978-1-4696-2816-5.

W hat is the function of a road; is it merely used to get from one place to another? In the case of the Outer Banks National Scenic Byway, a road facilitates interaction and learning. Authors Barbara Garrity-Blake and Karen Willis Amspacher present not just a travel guide to navigating the byway along the diverse Outer Banks, but they provide a native's deep insight into the history and culture of a place where change, forced by the sea itself, has always been inevitable. Perhaps now, though, changes faced by its inhabitants are even more transformative and dramatic due to other factors, and as Amspacher asserts, it is her "daily struggle to protect and defend my community of communities." Indeed, the book is also a call to arms of sorts, advocating for preserving the traditions and environment of the villages comprising this area. Ultimately, the tone is both celebratory and poignant.

The authors make an effective pair: their individual backgrounds are divergent, lending an interdisciplinary approach to the presentation. GarrityBlake is an anthropologist and, in comparison to her co-author, a relative newcomer to the area. Amspacher is a native and resident of Marshallberg, whose family goes back many generations. What both share is a wonder and passion for their home. Garrity-Blake may be an academic, but the writing style is down-to-earth and conversational. Every aspect of life is covered, with just enough detail to satisfy, and vivid descriptions draw the reader in.

The book is organized into the building blocks that form the community, starting with water, then land, then people. This emphasizes that the physical environment is crucial to this area's community-building and traditions. Sections begin with a charming quote from a native regarding the subject at hand. There is an effective mix of current-day and historical tidbits. Sections called "sidebars" feature primary sources, snippets from other published materials, photographs, and the like. Each is well-cited and balances out the more anecdotal passages. Additionally, at the end is a helpful list of "further reading" recommendations.

A tension regarding change does run throughout the text: "Many families face the realities of living in a vacation destination while trying to maintain their traditional way of life." While the book does slip at times into nostalgia that may not be entirely objective, it is made clear that the addition of non-native people to the communities is not the problem, rather they welcome the reader to visit, but with respect and appreciation, and as a result, merge with what already exists.

This guide is a love letter to the coast of North Carolina. Its inhabitants offer poetic descriptions of events and of the land and these are recounted with care. It is suitable for those interested in traveling to the region and for those doing more in-depth research. The genre is "travel guide," however, it is also an essential reference book for the area, and one that, unlike your typical guide, you can read cover to cover with ease.

\section{Sarah Carrier \\ University of North Carolina at Chapel Hill}

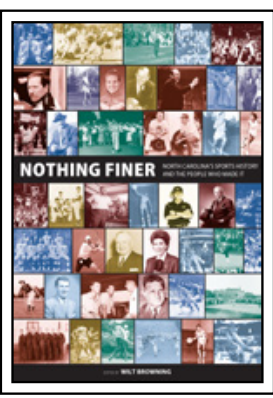

Nothing Finer: North Carolina's Sports History and the People Who Made It

By Wilt Browning, Ed.

Durham: Carolina Academic Press, 2014. 402 pp. \$35.00. ISBN 978-1-61163-608-6.

When folks think of the sporting life of North Carolina, most would point to the state's many successes on the hard court in college basketball. Pressed a little further, others may think of the history of NASCAR and how motor car racing has become a vital part of North Carolina life. However, North Carolina's achievements in sports are long and numerous, from the beginning days of horse racing to the recent establishment of three major sports teams and the successes of 
numerous minor league teams and interscholastic teams.

Nothing Finer contains an incredibly rich collection of essays covering North Carolina's most well-known sports and sports figures. Written by a collection of multi-award-winning sports writers from across the state, the history of sporting life is well presented. The combined experiences of these great sports writers covers over 300 years and comes out through the depth of storytelling of each writer.

Nothing Finer gives the reader the background of sports in North Carolina from a historical perspective, reaching back to colonial days and continuing forward to today's athletes and sports. Each chapter deals with either a particular sport or sports topic. While many of the chapters cover some familiar territory, one great entry is dedicated to the state's interscholastic achievements. Written by Tim Stevens, the prep sports chapter includes fascinating accounts of high-school sporting figures and teams that aren't easily found in other sources. There is a complete list of championship teams from various colleges and universities compiled as of December 31, 2013, as well as an index of names allowing for quick access to your favorite athlete's entries.

Nothing Finer covers each individual sport and various athletes thoroughly. Throughout each chapter there are mentions of both male and female athletes and team heroics. However, here's hoping to a follow-up in the coming years that will include a few more essays devoted entirely to the achievements of female athletes in the state of North Carolina. This book is suitable for public and academic libraries. All libraries in North Carolina should consider purchasing for sports fans and history buffs.

\section{Calvin Craig \\ Gaston College}

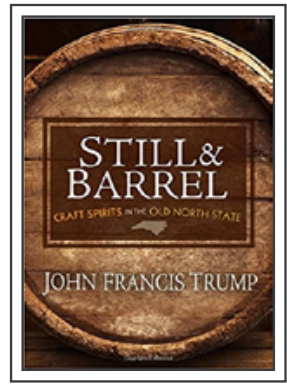

\section{Still \& Barrel: Craft Spirits in the Old North State}

By John Francis Trump.

Winston-Salem: John F. Blair, Publisher, 2017.

200 pp. \$19.95. ISBN 978-0-89587-683-6.

$\mathrm{I}^{\mathrm{n}}$ n Still \& Barrel: Craft Spirits in the Old North State, John Trump offers readers a glimpse into the craft spirit industry in North Carolina. Visitors to some North Carolina towns like Wilkesboro often hear its nickname "Moonshine Capital of the World." In Prohibition days, distillers of moonshine in the vicinity of Wilkesboro could only make their product when the moon was "shining." Along with these historical tidbits, the author traces some legislation and associations in the state which have enabled distillery operators to manufacture craft spirits in North Carolina successfully. Ultimately, the passage and signing of House Bill 909 by Governor Pat McCrory (2015), the Distillers Association of North Carolina, and the "NC Craft Distillers Trail" have aided the North Carolina distilling industry. Readers are encouraged to obtain a North Carolina distillery passport which will enable them to visit distilleries and get a "stamp" on their passport. Additionally, the author includes a "distilling primer" which lists the most popular spirits dispensed by North Carolina distilleries: brandy, gin, liqueur, moonshine, rum, vodka, and whiskey.

Trump structures his book by listing 36 distilleries across the state. Each chapter introduces readers to the owners of the distillery, a brief history of the company, specific manufactured products, etc. Numerous pictures of both the owners of the distillery working the "stills" and their products are provided. Some sample names of North Carolina distilling companies mentioned in the book include the following: "Howling Moon" (Asheville), "Doc Porter's Craft Spirits" (Charlotte), "Call Family Distillers" (Wilkesboro), "Mayberry Spirits Distillery” (Mt. Airy), "Top of the Hill Distillery" (Chapel Hill), "Mother Earth Spirits" (Kinston), and "Outer Banks Distillery” (Manteo). The author includes a map of distillery centers across the state, specific distillery photographs, and an index. Finally, Trump lists the distillery name, contact address and telephone number, and touring hours for each distillery.

John Francis Trump is a graduate of Goucher College in Baltimore, Maryland, and a resident of Madison, North Carolina. The author began his study of distilleries with a few blogs on a personal website (halfwaysouth. com) and the blogs were eventually included on the Huffington Post website (http://www.huffingtonpost.com/). Still \& Barrel evolved from a thesis that the author wrote about the craft distilling industry in North Carolina.

This book is intended to help readers gain a better understanding about the history and variety of distilleries which manufacture different alcoholic beverages across North Carolina. Because of its specific scope and subject matter, Still \& Barrel would be suitable for inclusion in any academic or special library with a collection focusing on North Carolina distillery industries.

\section{David W. Young \\ University of North Carolina at Pembroke}




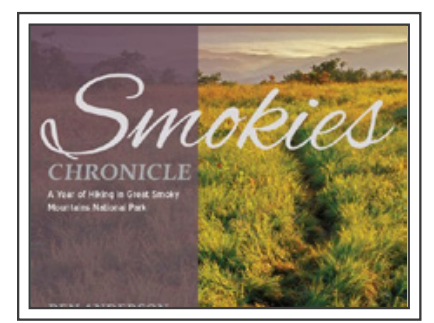

Smokies Chronicle: A Year of Hiking in Great Smoky Mountains National Park

By Ben Anderson.

Winston-Salem: John F. Blair, 2017. 208 pp. \$19.95. ISBN 978-0-89587-693-5.

$\mathrm{P}$ robably the best destinations for travel are those you can visit repeatedly and still see something new each time. That would be the case for the Great Smoky Mountains National Park, according to author Ben Anderson. Anderson recounts his hiking experiences on forty separate trails in the park's system, adding valuable history with a naturalist's eye along the way. His most obvious audience would be those in need of recommendations for hiking in the park, but the book would also appeal to those who are interested in the environment and outdoor culture of Western North Carolina and Eastern Tennessee.

The book is a project meant to celebrate the National Park Service Centennial in 2016. Anderson set out to hike three or four days a month, with ten outings a season, and document the experience. Anderson includes a total of forty hikes in the book, narrating each hike in an approachable way, peppered with anecdotes about the weather or characters met along the way. The anecdotes are entertaining, although perhaps not of use for someone looking for hiking advice. But practical information is very much interwoven in the tales the author recalls.

The introduction includes information about the history of the National Park Service and the Great Smoky
Mountains park itself. In addition to a standard index, the author provides two other helpful lists: favorite hikes by month, and favorite lookouts. It becomes apparent quickly that the book is not intended to necessarily be read from cover to cover, but then again, it could be, to get ideas about what trails to try. An even better idea would be to consult the special lists, or, determine an access point via the book's map, particularly since the park strides the Tennessee/North Carolina line, and some trails may not be reasonable to try. And, of course, considering how much time is available to hike, or how difficult the trail is.

It is recommended that the reader access the various hikes via the index. For example, if you are interested in a particular activity in addition to hiking, like tubing, this appears in the index. The author has a sense of humor, as evidenced by him including "Bolt, Usain" in the index. This is referencing the speed that boars can run, as boars can be a frequent sight in the park. Do you want to see animals on the trail? For example, wild turkeys? Simply look up the animal in the index to see where the author sighted one.

Ben Anderson is a retired professor and public relations specialist who lives in Asheville. He has written for several news outlets, including the Asheville Citizen-Times. Anderson has delved into other genres of writing, including fantasy. An experienced hiker with decades of experience as a volunteer in the Smokies, he taps into his expertise to make recommendations to hikers of various skill levels regarding what trails to traverse, while utilizing a readable and personable style.

\section{Sarah Carrier \\ University of North Carolina at Chapel Hill}

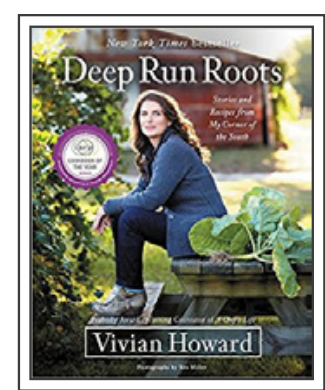

Deep Run Roots: Stories and Recipes From My Corner of the South

By Vivian Howard.

New York: Little, Brown, 2016 564 pp. \$40.00. ISBN 978-0-316-38110-9.

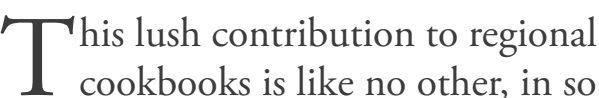
many respects. It is a labor of love as well as a serious documentation of Eastern North Carolina's food ways. Vivian Howard, the well-known and popular host of the PBS TV series "A Chef's Life," and proprietor of the Kinston, N.C. restaurant, the Chef and the Farmer, has achieved something incredibly special with this book. This is not "just" a cookbook. It is a beautifully written memoir and rebuke to Thomas Wolfe's concept that "you can't go home again." Vivian Howard came home (and in a big way) and is here to tell you why it matters to her, her family and to the region.

The book's introduction is aptly entitled "Don't You Dare Skip This Introduction!" And really, you shouldn't. In her own words, which explains the book better than anything this reviewer can say, Howard details why she wrote the book and what she hopes to achieve. "This is the story of my life so far, told through the ingredients that fill the plates and pantries" of this part of the state. Deep Run is a "nondescript dot on Eastern North Carolina's flat coastal plain.” In spite of this and because of it, Howard proclaims that after leaving her tiny community (not a town; it's a fire district) she returned with a deeper appreciation 
for the food, the culture, the people and especially, her immediate family.

The arrangement of this book is different from many cookbooks. Howard explains, "This is a storybook as much as it is a cookbook, where the ingredients are characters that shape my life."

The ingredients included in this book are pure Eastern North Carolina and they are addressed in depth. Imagine my delight to find a whole chapter featuring Muscadine grapes - an ingredient not found in many cookbooks at all, ever. This reviewer has several baggies of these grapes in her freezer with no clue what to do with them.

The book is divided into chapters that focus on certain foods - most particularly fruits and vegetables, although one chapter is devoted fittingly to sausage, another one to eggs. There is a separate recipe guide to help find dishes in an alternative fashion, which is incredibly helpful, along with a traditional index. You can find anything 6 ways to Sunday.

The whole volume is chock full of gorgeous pictures of interesting dishes. The photographs do not dominate as much as they complement the narrative. The medley of dishes contain traditional, old-fashioned selections alongside more nuanced and creative new offerings. Here one can find a classic deviled egg recipe, for example, but then along comes Collard Dolmades with Sweet Potato Yogurt. This volume both instructs and entertains, in equal measure. In other words, if you are "from around here" and want to check out the book for its bona fides, you likely will come away impressed. If you are a discerning foodie from some urban center, you too may find recipes or ingredients here worth sampling. There seriously is something for everyone in this book.

The celebration of the region is part of the book's unique charm. Eastern North Carolina is often heralded for its vinegar-based pork BBQ but most other common dishes are usually lumped into the basic category of "Southern." This book documents the special and/or peculiar dishes of the region in the best way possible.

The heft of this volume is impressive; it weighs in at 564 pages, making the $\$ 40$ price tag actually quite a steal. Every library in North Carolina should endeavor to have this book on their shelves, and all libraries east of I-95 for sure.

\section{Eleanor I. Cook \\ East Carolina University}

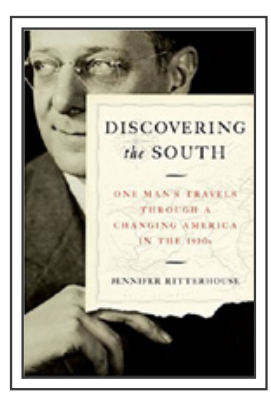

Discovering the South: One

Man's Travels through a Changing America in the 1930s

By Jennifer Ritterhouse.

Chapel Hill: University of North Carolina Press, 2017.

363 pp. \$34.95 hardcover; $\$ 33.99$ e-book.

ISBN: 978-1-4696-3094-6 hardcover;

978-1-4696-3095-3 e-book.

Tn 1937, Jonathan Worth Daniels (1902-1981), editor of the Raleigh News and Observer, took an extensive driving trip to parts of ten Southern states. Daniels was Caucasian, liberalleaning, and a future press secretary to President F.D. Roosevelt. He suspected that the real South might defy popular assumptions, and he wanted to find out first hand. He encountered a region poised for change yet struggling with poverty exasperated by the Great Depression and with racial divisions unhealed since Reconstruction. Daniels's book about the trip, $A$
Southern Discovers the South, was published by Macmillan in 1938.

Jennifer Ritterhouse, Associate Professor of History at George Mason University, has expanded upon Daniels's account by incorporating meticulous archival research, Daniels's unpublished notes, and her own perspective as a twenty-first century historian to create a nuanced and thoughtprovoking discussion of Daniels's journey.

As a PhD in History from UNCChapel Hill and the author of numerous publications on twentieth-century history in the Southeast, Ritterhouse is well-positioned to place Daniels's observations and conclusions in contemporary context. In addition, she has performed the admirable feat of making an erudite work of scholarship engagingly readable.

The book includes extensive notes, a full bibliography, a functional index, photographic illustrations, and a map. The companion website at http://discoveringthesouth.org/ includes synopses, a graphical retracing of Daniels's journey, additional photographs, links to archival material, and suggestions for using the book and website for teaching.

Recommended for academic libraries with strong collections in Southern history and twentieth-century U.S. history.

\section{Elaine Yontz}

East Carolina University

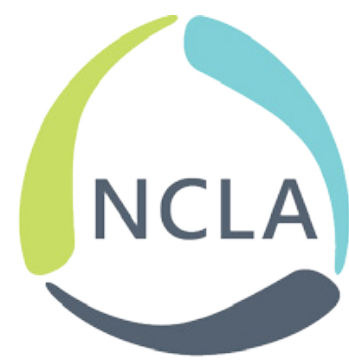

North Carolina Library Association 